\title{
El Grupo Andino en el proceso de integración latinoamericana*
}

CARLOS F. D I Z ALEJANDRO cs nacido en La Habana, educado en Estados Uniclos (Mr.I.T.). En 1959 trabajó en el Ministerio de Economía de Cuba. Actualmente es profesor asociado de economía en la Universidad de Minnesota. Asesoró al Comité de los Nueve de la Alianza para el Progreso y fue profesor auxiliar en la Universiclad de Yale entre los años 1961-65. Entre sus publicaciones está Exchange Rate Devaluation in a Semi-Industrialized Economy: The Exiperience of Argentina, 1955-1961, м.1.T. Press, I965.

Las dificultades experimentaclas por la Asociación Latinoamericana de Libre Comercio (ALALC) en sus esfuerzos por impulsar la integración de la zona, han sicto las causas inmediatas que explican la creación clel Grupo Andino, cuyo nacimiento puede fecharse con la Declaración de Bogotá de agosto de 1966. Esta declaración fue suscrita por los presidentes de Chile, Colombia y Venezuela, y por los representantes de Ios del Perú y Ecuador. En agosto cle 1967, Bolivia también firmo la Declaración. El propósito de este artículo es el cle describir y evaluar someramente las actividades, planes $y^{\prime}$ perspectivas del Grupo Andino, principalmente enfocadas descle un punto de vista económico.

\section{Algunas CARActerísticas de los Pajses QUe INTEGRAN EL Grupo Andino}

Convendrá ubicar la posición relativa del Grupo Andino dentro del conjunto latinoamericano antes de clescribir sus actividacles. Los seis países, con aproximaclamente sesenta millones de habitantes, representan un 24 por ciento de la población de América Latina, y un 27

* He preparado este trabajo mientras participaba en un programa conjunto de la Oficina de Planificación Nacional de Chile, y el Centro de Estudios Internacionales del Instituto Tecnológico de Massachusetts. Pero la responsabilidad por las opiniones presentadas es mia cxclusivamente y ellas puedon, no ser compartidas por las instituciones señaladas. El seminario sobre Integración Económica y Política, celebrado en Arica del 23 de encro al 2 de febrero de 1968, me ayudó a clarificar y definir mis ideas sobre el tena. Agradezco también valiosos comentarios de la Srta. Ana María Jul. 
por ciento de su superficie ${ }^{1}$. Su producción mineral domina en la re. gión; aportan el 50 por ciento del carbón, el 65 por ciento del hierro, el 83 por ciento de petróleo crudo y el 90 por ciento del cobre y estaño producidos en América Latina. Por otra parte, su participación en la producción agropecuaria cae por debajo de aquella correspondiente a su población; por ejemplo, los seis países sólo contribuyen alrededor del 15 por ciento de la producción de carne bovina, de arroz y de trigo, un 8 por ciento de la de maíz, y un 12 por ciento de la producción de algodón y lana. Además, entre 1958-60 y 1961-66, la producción agropecuaria per capita del Grupo Anclino tomado en conjunto ha permanecido prácticamente constante y la subregión es importadora neta de carne, cereales y productos lácteos. En el sector manufacturero predominan las industrias que se han clado en llamar vegetativas y se nota cierto atraso, en comparación con los tres grandes de la zona (Argentina, Brasil y México), en el desarrollo de las actividades metalmecánicas y otras agrupaciones dinámicas. Por ejemplo, la producción de los países andinos sólo representa del 15 al 17 por ciento de la producción latinoamericana del arrabio y acero². Una de las causas principales de ese atraso relativo ha sido lo limitado del mercado de cacla país tomado aisladamente (aun en el caso de Venezuela, que tiene el más alto ingreso per capita). Con el establecimiento de la subregión, se crea un espacio económico cuyo Producto Nacional Bruto para 1966 puede estimarse en más de treinta mil millones de dólares, cifra similar a la correspondiente al Brasil, y superior a la de Argentina?.

El Grupo Andino, desde luego, no es perfectamente homogéneo. En particular, pueden distinguirse tres pares de países: Chile y Colombia,

2Los datos mencionados en este artículo, cuando no se indique lo contrario, provienen de Naciones Unidas, Boletin Estadistico de América Latina, Vol. iv, No 1, febrero 1967, y se refieren a 1965 ó 1966. Por "América Latina" se cntiende las veinte repúblicas.

PPara 1960 puede estimarse que las agrupaciones vegetativas del sector manufacturero del Grupo Andino aportaron el 23 por ciento del total de la producción latinoamericana en esos sectores, pero el aporte fue de sólo un 17 por ciento en el caso de has agrupaciones dinámicas. Datos obtenidos de Naciones Unidas, El Proceso de Industrialización en Amórica Latina, Anexo Estadistico (z/cN. 12/716/Add. 2), páginas 64-68. Sin embargo, en dos importantes industrias de base, electricidad y cemento, la participación andina en 1965 fue del 26 y el 31 por ciento, respectivamente. La producción andina de electricidad en 1966 superó a la argentina en un 77 por ciento, y a la mexicana en un 41 por ciento; la de cemento superó a la brasileña en un 30 por ciento en 1965.

aEl cálculo del Producto Nacional Bruto se lia hecho tomando tipos de cambio de paridad para 1962, estimados por la Comisión Económica para América Latina, y proyectando el crecimiento del producto para 1962-66. En 1965 la producción de acero y elcctricidad en cl Brasil superó a la andina, pero las importaciones y la producción de cemento del Grupo Andino excedieron ampliamente las correspondientes cifras brasileñas. Ls interesante señalar que, en contraste con el Brasil, la subregión muestra un producto per capita superior y una mayor diversificación regional. Véase también Rodrigo Botero, La Comunidal Económica CaribemAndina (Bogotá, 196i: Ediciones Tercer Mundo), pp. 22 y 99-101, para otros cálculos sobre el producto $y$ Ia producción regional. 
de economías relativamente cerradas y con una política proteccionista de larga tradición; Perú y Venezuela, con economías más abiertas, pero contanclo también con importantes sectores manufactureros; y Ecuador y Bolivia, cuyas economías reflejan un menor grado de desarrollo que las de los otros cuatro países. Tomaclos conjuntamente, los andinos representan alrededor de un 40 por ciento del comercio exterior latinoamericano, pero excluyendo a Venezuela, la participación cae al 21 por ciento.

El desarrollo industrial de la subregión durante los últimos años ha sido más rápido que para América Latina en su conjunto. Durante 1961-1966 la producción de electricidacl creció en un 56 por ciento en la subregión y sólo en un 4.I por ciento en el resto de América Latina; entre 1960 y 1965 las tasas cle crecimiento en la producción manufacturera de cada uno de los andinos, superaron con creces las correspondientes a Argentina y Brasil. Este mayor dinamismo inclustrial puede llegar a ser un factor importante para suavizar el impacto de los ajustes $y$ desequilibrios que pueda provocar un programa acelerado de integración económica.

Finalmente, cabe señalar que, tomaclas en su conjunto, las actuales estructuras políticas andinas se comparan favorablemente con las del resto de la zona en cuanto a su representatividad y flexibilidacl. Este factor, junto con la obvia estrechez cle los mercados nacionales $y$ el temor a convertirse en la "periferia" cle los grandes centros industriales en Argentina, Brasil y México, han fortaleciclo la voluntad política de estos países para acelerar la marcha de su integración. Es también interesante que varias de las personaliclades más importantes en la creación del grupo se conocieron y entablaron lazos cle amistad durante los primeros años de la Alianza para el Progreso, cuando se multiplicaron los contactos entre latinoamericanos.

\section{Actividades y Programas del Grupo Andino}

La realización de los acuerdos de la Declaración de Bogotá quedó pendiente de la celebración de la reunión de presidentes en América, la cual, después de ser aplazada varias veces, se efectuó en abril de 1967. Una vez lograda la aprobación de los presidentes latinoamericanos a la existencia del Grupo Andino dentro de ALALc, que fue confirmada por sus cancilleres en Asunción, fue constituida una comisión mixta, compuesta por representantes personales de los presidentes de los países firmantes del Acta de Bogotá, encargada de ejecutar un plan integracionista cle acción inmediata. Esta comisión se reunió por primera vez en Viña del Mar en junio de 1967 y durante el

$$
\left[\begin{array}{lll}
2 & 4 & 4
\end{array}\right]
$$


Carlos F. Díaz Alcjandro / El Grupo Andino en el proceso de Integración Latinoamericana resto del año 1967 se celebraron tres reuniones más (en Quito, Caracas y Bogotá). La quinta reunión de la comisión se llevó a cabo durante febrero de 1968 en Bogotá.

El plan integracionista que está sienclo elaborado por la comisión mixta y su grupo de expertos parece consistir en dos grandes líneas.

La primera intenta acelerar la liberalización del intercambio entre los seis países y crear un arancel extemo común. El programa de liberación tiene como objetivo la eliminación de todas las restricciones y gravámenes que incidan sobre la importación de bienes originarios de cualquier país andino. En contraste con el engorroso procedimiento cle ALALC, se utilizarán mecanismos automáticos e irreversibles para desgravar la mayoría de los bienes, sin necesidad de negociar proclucto por producto. Exceptuando productos sometidos a regímenes especiales por el Trataclo de Montevideo, en su mayoría bienes agropecuarios, la liberación total sería alcanzada en un plazo máximo de cloce años a partir de la vigencia del Acuerdo Subregional. Los expertos que preparan el Acuerclo esperan tenerlo listo para la firma de los gobiernos a fines cle abril de 1968. El Acuerclo incluirá un tratamiento especial para Bolivia y Ecuador, países que recibirán concesiones con mayor rapidez, mientras que podrán demorarse más en reducir sus restricciones. Las bases del programa de liberación, aprobaclas en febrero de 1968, también contemplan la liberación total de los bienes incluidos hasta ahora en la Lista Común de ALALC dentro de un plazo de 180 días a partir cle la fecha de entrada en vigencia clel Acuerclo, así como una rápicla liberación cle productos que no se producen en la actualidad en ningún país de la subregión. La elaboración y composición final de la lista de estos productos dará una buena indicación de cómo el entusiasmo integracionista andino resiste sus primeros encuentros con decisiones clifíciles. En la actualidad se prevé que tal lista será muy amplia, y que la definición formal de los procluctos que ahora no se producen en la subregión será liberal. Fuera cle una parte reservada para Bolivia y Ecuador, la posibiliclad cle empezar a producir los bienes, en la lista para todo el mercado andino quedará abierta, sin mayores complicaciones, a cualquier país de la subregión. Ha sido precisamente por falta de un amplio y seguro mercado que la mayoría de esos bienes no se han comenzado a producir en los países andinos. De firmarse el Acuerdo Subregional en junio de 1968, las primeras reducciones arancelarias se llevarían a cabo a principios cle 1969 .

Aunque se espera concertar acuerclos cle complementación cada vez. más perfeccionados en varias inclustrias claves, tales como la química 
y petroquímica (donde las negociaciones ham avanzaclo considerablemente), metalurgia básica y la automotriz, que planifiquen la integración de esas actividades, clonde sea posible en coordinación con ALALC, existe inquietud e interés de evitar que se obstaculice la inclusión de los productos de esas industrias en los mecanismos generales cle desgravación, en caso que los acuerclos de complementación no se adopten, o no cubran todos los productos del sector. La intención del Grupo parece ser la cle utilizar tanto la planificación como las fuerzas del mercado para acelerar la integración, tomanclo una actitud flexible $y$ pragmática en cuanto a la esfera de acción de cada uno de esos instrumentos. El supuesto básico es que los andinos juntos podrán crecer a un ritmo superior a lo que sería posible de permanecer aislados, y que, por lo tanto, existirá la voluntad cle tomar las medidas que sean necesarias para corregir, sobre la marcha, los desequilibrios y fricciones que pueclan surgir en el futuro. Más que tratar de planificar cada detalle cle la integración, se crean instituciones que se espera ayuclen a sortear escollos ahora visibles sólo en forma muy general.

Una institución clave será la Junta Ejecutiva Permanente, que actuará como el secretariado del Acuerclo Subregional, vigilando en forma continua la marcha cle la integración. La Junta, que las bases aprobadas recientemente denominaran "el órgano técnico-comunitario del Acuerdo Subregional", contará con tres miembros, quienes en sus funciones deberán responder solamente a los intereses comunitarios, $\sin$ solicitar o recibir instrucciones de gobiemos. O sea, la Junta solamente sexá responsable por sus actos ante la comisión mixta, que es el órgano máximo del Acuerdo, y la cual cleberá reunirse por lo menos tres veces al año. Podrán ser miembros de la Junta, nacionales de cualquier país latinoamericano, mientras que la comisión mixta seguirá siendo constituicla por representantes plenipotenciarios de los países. La Junta, cuya secle probablemente sea Bogotá, podrá presentar iniciativas para la consideración cle la comisión mixta, y en coordinación con lá corfo Andina, planificará y guiará la marcha de la integración, ayudando a solucionar los problemas que se vayan presentando. En particular, de quedar rezagado algún país andino en cuanto a los beneficios obtenidos de la integración, la Junta deberá proponer medidas que corrijan tal situación.

Una de las tareas de la Junta Ejecutiva Permanente será la creación de un arancel externo común. La transición en cada país de un sistema proteccionista inclepencliente a un arancel externo común, se hará en dos pasos. El primero, que deberá tomar no más de cinco años a partir de la vigenciá del Acuerdo Subregional, consistirá en la crea- 

ción de un arancel común mínimo, que garantice a todos los productores andinos un moderado margen preferencial contra la competencia externa. Al sexto año de vigencia del Acuerdo, mediante un proceso automático $y$ lineal, se cleberá iniciar la aproximación final al arancel común, que incluirá la universalidacl de los productos. Para complementar estos acuerclos comerciales, se estuclia la creación de mecanismos financieros de corto plazo, como una Cámara de Compensación. A fin de que toclos los productores andinos puedan disfrutar de una igualdad de oportuniclades ante la desgravación comercial, y para preparar el camino hacia una integración económica más estrecha, también se estudian medidas que tienclan a armonizar políticas fiscales y monetarias. En particular, habrá que establecer "reglas del juego" sobre las políticas cambiarias andinas.

Para facilitar contactos con el sector privado andino, la comisión mixta ha aceptado como organismo consultivo un comité formado por empresarios. Es previsible que la Junta Ejecutiva Permanente mantendrá estrechos contactos con este grupo.

Es sólo superficialmente paradojal que en una década caracterizada por la aceptación de la planificación, el Grupo Andino proponga una liberación acelerada y automática del comercio subregional. Es precisamente porque se ha aprendido que en economías mixtas la planificación debe concentrarse con prioridad en actividades en las cuales las fuerzas del mercado operan mal o débilmente, que se descentraliza parte de la responsabilidad por acelerar la integración. El Grupo Andino planificará, pero flexiblemente y consciente de que la planificación no es siempre ni la vía más rápida, ni la más éficiente para lograr un objetivo. Una de las formas más seguras de frenar la integración sería tratar de prever y planificar minuciosameinte cada uno de sus pasos y el insistir que no se tomen mediclas hasta completar estudios exhaustivos industria por inclustria (estudios cuyos datos quedarían obsoletos en la mayoría de los casos antes de completarse). Resulta difícil predecir ex-ante qué país debe especializarse en cada actividad y la historia económica enseña que frecuentemente son iniciativas aventuraclas de empresarios públicos o privados, las que crean una provechosa especialización.

El Grupo Andino ha enfatizado que sus acuerdos tienen sólo un carácter transitorio, ya que eventualmente quedarían fusionados con el proyectado mercado común latinoamericano. También se ha evitado que los arreglos andinos estén en conflicto con las regulaciones existentes de AlALC y se mantiene la puerta abierta a la cooperación con otros países latinoamericanos. Pero no hay clucla que existe un gran escepticismo sobre la rapidez con que avanzará el mercado co- 
E S T U DIOS INTERNACIONALES

mún latinoamericano. Según el acta de los acuerdos de la reunión de presidentes en abril de 1967, el mercado común latinoamericano se pondrá en marcha en 1970 y será completado en un plazo no mayor de 15 años. Si se toma al pie de la letra esta declaración, la creación clel Grupo Andino tendría una importancia limitacla, ya que a lo más aceleraria el logro de la meta integracionista por unos pocos años.

\section{IA CORFO ANDINA}

Pero la subregión no limita su plan a acelerar la desgravación y liberación del comercio. La segunda gran línea del plan ha culminado en la creación de la Corporación Anclina de Fomento, realizada en febrero de 1968 (aunque todavía pende su ratificación), después de haber sido objeto de estudios y consultas durante 1967. La corfo Andina es la primera institución financiera multinacional de largo plazo totalmente latinoamericana, y cuya sede estará en una capital latinoamericana, Caracas. Su creación explícitamente une al objetivo de integración, el de un desarrollo fomentado por inversiones, especialmente en proyectos multinacionales. Además de su función financiera, en lo que cuenta con amplias facultades para emitir diversos valores, obtener créditos y dar garantías, pudiendo captar fondos públicos o privados, latinoamericanos o extranjeros, la corfo Andina servirá de centro dinámico para otras actividacles orientadas a impulsar la integración y el desarrollo. Por ejemplo, mediante reuniones periódicas con los directores de planificación de los países y la Junta Ejecutiva Permanente, podrá ayudar a coordinar y dirigir el crecimiento de agrupaciones industriales claves, cuya expansión económica requiere de forma especial amplias escalas de producción. También podrá cooperar en la realización de tal planificación, estudiando, preparando y financiando proyectos multinacionales de complementación, y promovienclo la organización o modernización de empresas cuando sea necesario. Es previsible que la corfo Andina pueda utilizarse, al menos en ciertos casos, como representante única de los seis países en negociaciones comerciales y financieras que puedan realizarse con países e inversionistas extranjeros, y con organismos internacionales. La institución podrá ser utilizada también para suavizar cualquier desajuste o fricción regional o sectorial que puecla surgir del programa de desgravaciones automáticas, debiendo a ese fin coordinar sus actividades con la Junta Ejecutiva Permanente. Mediante una acertada distribución de sus inversiones podrí, en particular, beneficiar a los países más débiles del grupo, Ecuador y Bolivia. Sería ineficiente, sin embargo, que la corro Andina se limitase a esta 
última tarea, ya que esos clos paises representan solamente un 16 por ciento de la población andina.

También se dedicará esta institución al desarrollo de infraestructura que apoye la integración, y de zonas fronterizas en clonde viejos resabios no han permiticlo el aprovechamiento de buenas oportuniclades económicas, y mediante ayuda técnica y financiera podrá socorrer a los empresarios y obreros cle actividades clañadas por el aumento de competencia que resultará del proceso de liberalización comercial. La corfo Andina, está muy claro, ha sido concebida no como un instrumento financiero internacional más, sino como un foco dinámico con capacidad para general y' ejecutar iniciativas propias.

El capital suscrito de la nueva institución es cle 25 millones de dólares, llegando el capital declarado a los 100 millones. Cada gobierno andino, o la institución que éste designe, suscribirá una acción de la serie "A", con un valor de un millón de dólares cada una. Los gobiernos también garantizarán la suscripción de acciones de la serie " $B$ ", por un monto de cuatro y medio millones de clólares, en el caso de Colombia, Ghile, Perú y Venezuela, y de medio millón de dólares para Bolivia $y$ Ecuador. Las acciones de la serie " $B$ " podrán ser efectivamente suscritas por personas naturales o juriclicas de derecho privado hasta un 40 por ciento de las que corresponclen a cada país. La idéntica contribución de los cuatro mayores países sustituyó una propuesta anterior que hubiera resultado en un mayor aporte venezolano.

EI resto del capital autorizado podrá suscribirse en el futuro mediante la emisión de nuevas acciones de la serie "A" (en caso del ingreso cle un nuevo país a la institución), de la serie "B" (que serían ofrecidas en primer término a los actuales accionistas), o de la serie " $\mathrm{C}$ ", destinadas a ser. suscritas por personas juriclicas o naturales de fuera cle la subregión.

El Directorio de la corfo Anclina estarí integraclo por once directores, seis de los cuales serán clesignados por los accionistas de la serie"A", o sea los gobiernos. Los cinco directores restantes serán elegidos por los accionistas de la serie " $\mathrm{B}$ ", en proporción a las acciones que posean.

De esta estructura se clesprende que los organizadores de la corro Andina prevén una importante participación de capitales privados andinos $y$ cle fondos extranjeros en el futuro financiamiento de la institución. Se espera aunar fructíferamente esfuerzos públicos y privados, andinos y extranjeros, en las inversiones que se lleven a cabo, pero manteniendo el control de la institución en manos andinas que representen el interés general, aunque el sector privaclo podría llegar a estar representado en el Directorio por uno o clos miembros.

$$
\left[\begin{array}{lll}
2 & 4 & 9
\end{array}\right]
$$


E S T U D I O S 1 N TER NACIO NALES

El convenio creando la corfo Andina probablemente será ratificado por los poderes legislativos de los seis países durante 1968, en cuyo caso, y a más tardar, la institución comenzaría sus operaciones a principios de 1969.

\section{Perspectivas de los Planes Andinos}

La estrategia basada simultáneamente en un programa acelerado de liberación comercial $y$ en la creación de instituciones como la corFo Andina, la Comisión Mixta y la Junta Ejecutiva Permanente, tiene grandes posibilidades de lograr sus objetivos. Como en todo movimiento de pinzas, la coordinación de las dos grandes líneas de ataque contra el subdesarrollo $y$ el aislamiento comercial es indispensable para el triunfo. Las pílcloras que resultarán a veces amargas a corto plazo y cuyos efectos positivos son difusos y de largo plazo, deberán ir acompañadas de inversiones que rápiclamente muestren resultados "visibles".

En algumos círculos empresariales y académicos andinos existen temores $y$ dudas sobre el programa automático y general de desgravación comercial. Este mismo tipo de temor existió en Francia e Italia antes de la creación del Mercado Común Europeo, y la historia ha demostrado que no tenía mucho fundamento. Probablemente ocurra lo mismo en el Grupo Andino. No hay duda que la liberación comercial traerá nuevas presiones competitivas para los empresarios, especialmente los de las inclustrias vegetativas (y en algunos casos los del sector agropecuario), ahora acostumbrados a manejar los mercados nacionales sin temor a la competencia internacional o regional. En el futuro, el consumidor chileno podrá escoger entre textiles hechos en Colombia y los nacionales, por ejemplo, mientras que el consumidor colombiano podrá incluir el vino chileno dentro de sus alternativas de consumo. La mayor competencia en industrias vegetativas productoras de bienes-salarios, podrá reducir los precios relativos de estos productos y así contribuir a mejorar la distribución del ingreso. Pero la transición hacia esa nueva situación de mayor especialización, eficiencia $\mathrm{y}$ bienestar ${ }^{4}$, no será tan violenta $\mathrm{y}$ destructiva como muchos temen por varias razones.

En primer lugar, a corto plazo tanto los empresarios como los consumidores no cambian sus planes con rapidez, unos por los límites

${ }^{4}$ Los incrementos en el bicnestar cconómico que pueden lograrse mediante la creación de intercambio generada por un mercado común cnire países semindustrializados parece, haberse subestimado en la literatura cconómica. Con frecuencia se olvida que países como los andinos han desarrollado durante los últimos treinta años industrias paralclas que presentan amplias posibilidades de especialización clentro de un mercado común. En las zonas fronterizas, por ejemplo, es fácil ver que existen ricas posibilidades de intercambio, que ahorn no son aprovechadas por la presencia de obstáculos artificiales. 
Carlos F. Diaz Alejandro / El Grupo Andino en el proceso de Integración Latinoamericana impuestos por la capacidad máxima de sus fábricas y por problemas de mercado, $y$ otros por la inercia y fuerza de las costumbres. Este corto plazo dará oportunidad a los empresarios menos eficientes a especializar su producción y a mejorar sus métodos de dirección y operación, que con frecuencia han quedado aletargados en situaciones cuasimonopólicas, fomentadas por políticas ultraproteccionistas que ya hace años desviaron la compra de muchos bienes de mercados internacionales hacia la producción nacional, y eliminaron totalmente su importación.

Es necesario también colocar la visión cle esta nueva situación de competencia en un marco clinámico y realista. Se ha notado que las industrias andinas han crecido a un alto ritmo durante los últimos años, $y^{\prime}$ aunque para algunas ramas inclustriales cle algunos países la liberalización andina sin ducla resultará en una disminución en su tasa de crecimiento, reducciones en el nivel absoluto de proclucción son mucho menos probables. O sea, daclo el dinamismo andino, es poco probable que la liberalización cree montos significativos cle capaciclad ociosa. De cualquier forma, además cle cláusulas cle salvaguardia, sería conveniente que la coRfo Andina establezca programas especiales cle créclitos y asistencia técnica para aquellos empresarios y trabajadores que puedan ser perjudicados por el programa de liberación. La sola existencia de tales programas serviría para clisminuir temores y acelerar la clesgravación, y probablemente la historia mostrará que no fue necesario recurrir a ellos con frecuencia.

En muchas industrias dinámicas los problemas planteados por la integración tienen otro carácter. Para los productos cle esas industrias, los países andinos todavía dependen en alto grado ( $y$ en algunos casos totalmente), de importaciones traídas de los países industrializaclos. Aunque se logren aumentar las exportaciones andinas a esos mercados ( $y$ existe para eso mucho más posibilidacles de lo que comúnmente se cree, sobre todo después que la integración consolide la inclustrialización $y^{\prime}$ si se siguen políticas adecuadas), es previsible que la producción subregional en las industrias metal-mecánicas, petroquímicas y de papel y celulosa, por ejemplo, aumenten a un ritmo mucho mayor que las importaciones de esos productos traídos clesde fuera de la subregión. Ya que las economías de escala son muy pronunciaclas en la manufactura cle la mayoría de esos bienes, no sería deseable una proliferación cle plantas. La planificación regional, coordinada por la Junta Ejecutiva Permanente y la corfo Andina, más una tarifa externa común que mantenga cierto grado de presión competitiva, serán con frecuencia los medios más adecuados para que la "nueva" sustitución regional cle importaciones se lleve a cabo

$$
\left[\begin{array}{lll}
2 & 5 & 1
\end{array}\right]
$$


E S T U D I O S I N TER NA C I O N AL E S

con relativa eficiencia, evitando los errores cometidos clurante la "vieja" etapa de sustitución a nivel nacional. Ya que la "nueva" sustitución se hará principalmente en el campo de bienes intermedios y de capital, un proceso ineficiente que eleve los costos de estos productos tendría repercusiones negativas muy amplias, y especialmente sobre los planes andinos de inversión y de exportación. Puede notarse que en 1964, cerca del 40 por ciento de las importaciones andinas consistian de materias primas y bienes intermedios, y un 33 por ciento de maquinaria y equipo.

Tanto para las inclustrias vegetativas como en las dinámicas, sería altamente conveniente que el Grupo Andino rápidamente defina una política común hacia la inversión extranjera. El temor a la liberación, y aun a la integración, también se origina en la preocupación cle que el proceso sea captado $y^{t}$ clirigiclo por empresas extrazonales (principalmente norteamericanas), que resulte en un debilitamiento cle la empresa latinoamericana $y^{\prime}$ en un incremento en el grado de dependencia externa de la región. Aceptando como meta latinoamericana un mayor grado de autonomía, el peligro es innegable. Parecería que para que la liberación comercial resulte en un fortalecimiento y modernización del empresario latinoamericano, y no en su extinción, habría que controlar las inversiones directas extranjeras, limitándolas en las llamadas ramas vegetativas. La creación de sociedades andinas multinacionales también facilitaría la vigorización del empresario privado. En las industrias dinámicas, doncle el aporte tecnológico de las inversiones extranjeras es muy importante, Ia corFo Andina podría actuar con frecuencia como agente de los seis paises y cle sus empresas públicas y privadas, en negociaciones con inversionistas extranjeros, para maximizar su aporte tecnológico y minimizar el costo $y^{\prime}$ la clependencia que eso implica. Se evitaría así la paradojal situación de muchos países donde la protección, justificada con argumentos nacionalistas, beneficia principalmente a empresas extranjeras.

La planificación regional también podría ser fructifera en la coordinación y eventual fusión de empresas públicas que ya operan a nivel nacional, a menudo con alto grado de eficiencia, en la producción de minerales sóliclos, petróleo, electriciclad, comunicaciones y transportes $\tilde{\breve{s}}$.

Estas empresas públicas andinas, obviamente, tendrían un gran po-

"El papel que pueden jugar las empresas públicas latinoamericanas en el proceso de integración es discutido en detalle nor Marcos Kaplan E. en Problemas del Desarrollo y de la Integración de América Latina (Editorial de la Universidad de Chile, Escuela de Derecho de Valparaiso, 1967), especialmente en pp. 147 a 203. Los paises andinos ya han comenzado a coordinar ciertas actividades de sus marinas mercantes y a promover una línea aérea de carga conjunta. 
Carlos F. Diaz Alejandio / El Grupo Andino en el proceso de Integración Latinoamericana der de maniobra y negociación, que podría llevar a una mayor "latinoamericanización" de la explotación de los recursos naturales y de la infraestructura cle la zona. También la educación y la investigación científica y tecnológica ofrecen ricas posibilidacles para una cooperación planificada.

Todo tipo de negociaciones con los grancles países $y$ bloques que predominan en el mundo comercial $y$ linanciero se beneficiarán de un fortalecimiento de la Junta Ejecutiva Permanente y de la corFo Andina. No es aventurado suponer, por ejemplo, que el Mercado Común Europeo negociará en forma diferente con un representante andino único, de la que hubiera empleado para tratar con seis representantes andinos aislaclos. Significativamente, los países andinos han decidido participar conjuntamente en la Feria Mundial de Osaka.

El entusiasmo $y$ espíritu regional mostrados en las reuniones del Grupo Andino han permitido rápidas negociaciones sobre temas que en reuniones de ALALC han causado interminables dificultades. Junto con la calidad técnica y ejecutiva cle la comisión mixta y cle sus expertos, ese entusiasmo permite mirar las perspectivas andinas con optimismo.

Pero la futura evolución clel Grupo Andino no está exenta de problemas y peligros. Una dificultad consiste en la marcada diferencia que existe entre el nivel tarifario y de restricciones a la importación de Colombia y Chile, por una parte, y de Perú y Venezuela, por otra. En el período 1963.65, las importaciones de bienes y' servicios representaron un 12 por ciento $y$ un 14: por ciento del Producto Nacional Bruto en Chile y Colombia, respectivamente, mientras que en Perú y Venezuela la cifra fue clel 21 por ciento y en Ecuador y Bolivia los correspondientes porcentajes fueron 18 y 25 por: ciento. Es probable que la tarifa externa común significarí un aumento en los derechos aplicados en el Perú, por ejemplo, y un descenso en los aplicados en Chile. Siguiendo el ejemplo, compras hechas ahora por peruanos en mercados internacionales serán desviadas hacia productores andinos, quienes usualmente y al menos por un tiempo, cobrarán precios superiores. Este costo, que podrá considerarse parte del precio pagado por lograr otras metas del proceso integracionista, cleberá ser comparticlo equitativamente entre los seis países, y reduciclo a niveles modestos con la cuidadosa selección de los sectores en clonde se buscará la sustitución de importaciones regional mediante la aclopción de una tarifa externa común racional ${ }^{0}$.

aEI concepto de reciprocidad, que con frecuencia se aplica cróneamente a un crecimiento equilibrado de importaciones y exportaciones zonales de cada país en la región, más bien debe aplicarse a la equitativa distribucion de los costos que puedan resultar del desvio de comercio 
La Junta Ejecutiva Permanente deberá vigilar a aquellas industrias andinas que gocen de sustancial protección para evitar que se conviertan en cargas permanentes para la economía de la subregión, que puedan dañar planes de inversión y exportación. La búsqueda de un equilibrio entre las metas de integración, eficiencia, balance geográfico y autonomía (que a menudo están en conflicto en tre sí), será uno cle los principales problemas que enfrentarán la Comisión Mixta y la CORfo Andina. Una cuantificación, aunque no sea muy precisa, de los costos y beneficios que cacla país puede esperar de la integración, sería una guía útil en esta tarea, y poclría reducir temores y cludas sobre el proceso. Cabe anotar que, en contraste al temor a una mayor competencia regional, el temor de muchos empresarios, especialmente en Perú y Venezuela, al encarecimien to de sus insumos, que ahora importan de mercados mundiales, tiene una mayor justificación social.

La transición de una situación donde cacla uno de los seis países andinos tiene un sistema de protección clistinto, a otro donde impera una tarifa externa común, requerirá ajustes en los tipos de cambios reales, más o menos fuertes para cada país, según su vieja estructura proteccionista esté más o menos lejos del nivel que sea estableciclo en la tarifa externa común. Además, ya que en el pasado la protección ha sido utilizada con frecuencia como una herramienta para solucionar problemas de balance de pagos, los países andinos tendrán que estar dispuestos a recurrir a variaciones en sus tipos cle cambio con mayor soltura, una vez que los acuerdos sobre una tarifa externa común entren en vigencia $y^{r}$ eliminen la posibilidad cle variar los derechos arancelarios unilateralmente. Estas consideraciones, más el hecho de que los países de la subregión tienen ( $y$ con toda probabilidad seguirán teniendo) cliferentes tasas cle inflación, inclican que una negativa a permitir flexibilidad a los tipos de cambio, pondría en serio peligro al plan integracionista.

El Grupo Andino parte de una situación de muy escaso comercio entre los países que lo integran. Por ejemplo, en 1965 sólo el 4,2 por ciento del intercambio comercial chileno se realizó con los otros cinco países andinosĩ. Habrá, por lo tanto, que realizar grancles esfuer-

del tipo indicado en el ejemplo. Sobre este punto, ver a R. Ffrench-Davis y K. B. Griffin, Comercio Internacional y'Politicas de Desarrollo Económico (México: Fondo de Cultura Económica, 1967), pp. 196-198. La igualdad de importaciones y exportaciones de cada pais andino con la subregión no debe considerarse como condición necesaria para una justa reciprocidad.

IUn 7,2 por ciento de las importaciones cliilenas provinieron de los países andinos durante ese año, pero sólo un 1,6 por ciento de las exportaciones se destinaron a esos países. Datos obtenidos de la Cámara de Comercio de Santiago de Chile, Comercio Exterior, Chile, 1965 (Ediciones periódicas del "Informativo", agosto 1966), pp. 424-425 y pp. 714-715. El que el nivel actual del comercio intrandino sea tan bajo no significa necesariamente que el intercambio potencial también sea bajo. La vieja política de sustitución de importaciones a nivel nacional, que ahora se trata de superar, es en gran parte responsable por ese reducido nivel actual del comer- 
Carlos F. Diaz Alejandro / El Grupo Andino en el proceso de Integración Latinoamericana zos para establecer nuevos contactos $y$ canales de comercializacióni $y$ financiamiento. Por otra parte, el transporte del nuevo comercio se verá facilitado por la amplia "carretera" formacla por el Pacífico y el Caribe, la proximiclacl de muchos grandes centros productivos andinos a esos mares, y la existencia cle frecuentes rutas marítimas en la costa del Pacífico.

Aunque el 84 por ciento de la población del Grupo Anclino vive en los cuatro países cle más peso económico, los cuales, a pesar de las diferencias ya notaclas $y$ de la gran importancia de Venezuela en su comercio exterior, no presentan radicales contrastes en sus niveles industriales, la marcha de la integración andina podría verse amenazada políticamente, si las primeras reducciones tarifarias resultan en el crecimiento de las exportaciones zonales de sólo algunos paísẹs, posibilidad que no puede rechazarse a priori. Acuerdos sobre una cámara de compensación, ritmos diferentes de clesgravación para países con déficit $y$ superávit, $y$ otros mecanismos de ajuste especiales, podrían disminuir la seriedad de este problema. El hecho de que, en un comienzo, los desequilibrios zonales tendrán poca influencia sobre las balanzas de pagos globales de los países andinos, también permite cierto optimismo. Además, la corro Andina podrá tomar en cuenta, hasta cierto punto, tales clesequilibrios comerciales en sus planes de inversión y en los nuevos acuerdos de complementación. Finalmente, de poderse mantener el equilibrio global de las balanzas de pago andinas mediante ajustes en los tipos de cambio, sería preferible permitir déficit y superávit regionales, antes que frenar la liberalización comercial, o antes de forzar un excesivo desvío de comercio para 10grar la igualdad monetaria en los flujos comerciales regionales. Debe tenerse en mente que un exagerado desvio del intercambio (o sea, sustituciones regionales de importaciones que no tienen posibilidad de eventualmente reducir sus $\operatorname{costos} a$, o por debajo de los niveles internacionales), también podrá tener un impacto político negativo, al encarecer los precios de bienes cle capital y de insumos industriales claves en varios países.

La integración andina no debe tomarse como excusa para descuidar el fomento de las exportaciones zonales al resto del munclo, ya que una rápida tasa de crecimiento en el producto subregional requerirá no sólo de un eficiente programa de sustitución cle importaciones, sino también de una creciente corriente de importaciones extrazonales. Sin descuidar exportaciones tradicionales, una mayor eficiencia y espe-

cio andino. $\mathrm{Y}$ es precisamente cuando los países que entran en un mercado común tienen estructuras cconómicas parecidas, pero potencialmente complementarias, cuando pueden esperarse aumentos importantes en el bienestar económico como resultado del mercado común. 
ES T U DIOS I N T E R N $A$ CIONAL E S

cialización en industrias andinas que ya no pueden calificarse como "incipientes", podría generar nuevas exportaciones de productos manufacturados hacia el resto del mundo. EI arancel externo común deberá tener cuidado para no encarecer los insumos de aquellas actividades que generen, o potencialmente puedan generar, clivisas internacionales.

La liberación comercial podrá crear problemas financieros a las haciendas públicas que dependen, de mayor o menor grado, de los ingresos provenientes de impuestos a la importación. Pero la magnitud de este problema parece ser pequeña, y su inciclencia será gradual. Además, si estimula la ejecución de reformas fiscales, este aspecto de la liberación comercial tendrá resultados positivos a largo plazo.

Visto descle un punto de vista latinoamericano, el Grupo Andino, no hay duda, presenta el peligro de crear intereses que luego se opongan a una integración más amplia. Por ejemplo, de desarrollarse una siderurgia andina que resulte menos eficiente que la brasileña, podría frenar una posterior especialización más eficiente de la siclerurgia latinoamericana. La geografía andina resulta algo caprichosa comparada con otros esquemas regionales; parecería más lógico, por ejemplo, integrar la inclustria automotriz chilena con la cle Córcloba en Argentina, que con la colombiana y la venezolana. A menor el espacio económico cubierto por un nuevo mercacto común, mayor la posibilidad de que lleve a costosas desviaciones de comercio. O sea, de la mismá forma que la "vieja" sustitución cle importaciones a nivel nacional creó intereses que ahora se oponen a la integración, se corre el riesgo de que la "nueva" sustitución a nivel subregional, cree intereses que se opongan a una más amplia integración. Pero dacla la experiencia de AlALC y los beneficios netos que pueden esperarse de la integración andina, éste es un riesgo que vale la pena correr. Aclemás, el Grupo Andino ha expresado repetidamente su intención de seguir participando en ALAIC, y de ninguna forma crear conflictos entre sus resoluciones $y^{\prime}$ las que pueda acloptar ALsLc para crear un Mercado Común Latinoamericano.

Durante abril y mayo cle 1968, temores a un programa automático y general de desgravación, especialmente entre empresarios venezolanos en industrias que utilizan mano de obra en cantidades relativamente abundantes, han demorado la preparación final y la adopción del acuerdo comercial andino. Probablemente el acuerdo será modificado para tomar en cuenta estas reticencias, aunque existe la posibilidad de que se siga adelante al ritmo previsto sin la participación venezolana. 
Carlos F. Diaz Alejandro / El Grupo Andino en el proceso de Integración Latinoamericana

No cleja cle ser interesante que mientras en unos paises algunos empresarios se quejan del alto costo de la mano de obra, en otros se señala la dificultad para importar maquinaria como un argumento en contra de la rápida liberación comercial regional. Nunca faltan argumentos para defencler posiciones monopólicas aunque simultáneamente se canten loas a la libre competencia.

En resumen, aunque no pueda probarse rigurosamente, puede decirse que el plan integracionista del Grupo Andino tiene un gran potencial para aumentar significativamente las tasas de crecimiento de sus seis países por encima de lo que aquello podrían alcanzar si cada uno siguiera una política de sustitución de importaciones aisladamente. Por otra parte, el plan anclino permitirá un mayor grado de autonomía subregional que la que cada país hubiera podido alcanzar de seguir políticas libre-cambistas y de total apertura hacia el exterior. 